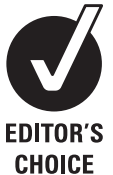

CHOICE

\begin{abstract}
- Additional data are published online only. To view this file please visit the journal online (http://dx.doi.org. 10.1136/imedgenet-2012101159).

${ }^{1}$ Mitochondrial Research Group, Clinical and Molecular Genetics Unit, UCL Institute of Child Health, London, UK

${ }^{2}$ Metabolic Unit, Great Ormond Street Hospital, London, UK ${ }^{3} \mathrm{MRC}$ Centre for

Neuromuscular Diseases, National Hospital for Neurology, London, UK

\section{Correspondence to}

Dr Shamima Rahman, Clinical and Molecular Genetics Unit, UCL Institute of Child Health, 30 Guilford Street, London WC1N 1EH, UK; shamima rahman@ucl.ac.uk
\end{abstract}

Received 6 July 2012

Accepted 28 July 2012

REVIEW

\title{
Complex I deficiency: clinical features, biochemistry and molecular genetics
}

\author{
Elisa Fassone, ${ }^{1}$ Shamima Rahman ${ }^{1,2,3}$
}

\section{ABSTRACT}

Complex I deficiency is the most frequent mitochondrial disorder presenting in childhood, accounting for up to $30 \%$ of cases. As with many mitochondrial disorders, complex I deficiency is characterised by marked clinical and genetic heterogeneity, leading to considerable diagnostic challenges for the clinician, not least because of the involvement of two genomes. The most prevalent clinical presentations include Leigh syndrome,

leukoencephalopathy and other early-onset neurodegenerative disorders; fatal infantile lactic acidosis; hypertrophic cardiomyopathy; and exercise intolerance.

Causative genetic defects may involve the seven mitochondrial-encoded or 38 nuclear-encoded subunits of the enzyme, or any of an increasing number of assembly factors implicated in the correct biosynthesis of complex I within the inner mitochondrial membrane. In this review, we discuss recent advances in knowledge of the structure, function and assembly of complex I and how these advances, together with new high-throughput genetic screening techniques, have translated into improved genetic diagnosis for affected patients and their families. Approximately $25 \%$ of cases have mitochondrial DNA mutations, while a further 25\% have mutations in a nuclear subunit or in one of nine known assembly factors. We also present a systematic review of all published cases of nuclear-encoded complex I deficiency, including 117 cases with nuclear subunit mutations and 55 with assembly factor mutations, and highlight clinical, radiological and biochemical clues that may expedite genetic diagnosis.

\section{INTRODUCTION}

Complex I (nicotinamide adenine dinucleotide $(\mathrm{NADH})$ :ubiquinone oxidoreductase, Enzyme Commission number EC 1.6.5.3) is the first and largest enzyme of the mitochondrial respiratory chain (RC) and oxidative phosphorylation (OXPHOS) system, and plays critical roles in transferring electrons from reduced $\mathrm{NADH}$ to coenzyme $\mathrm{Q}_{10}\left(\mathrm{CoO}_{10}\right.$, ubiquinone) and in pumping protons to maintain the electrochemical gradient across the inner mitochondrial membrane. This electrochemical gradient, generated by complexes I, III and IV, is subsequently harnessed by complex V (ATP synthase) to synthesise ATP from ADP and inorganic phosphate. Complex I is also the major site for the generation of reactive oxygen species (ROS), which are increasingly recognised to be important signalling molecules determining the health and fate of the mitochondrion and of the whole cell.

Isolated deficiency of complex I is the most commonly identified biochemical defect in childhood- onset mitochondrial disease, accounting for approximately a third of all cases of OXPHOS disorders. ${ }^{1}$ Complex I deficiency is clinically heterogeneous but the majority of affected individuals develop symptoms during the first year of life and have a rapidly progressive disease course, resulting in a fatal outcome in childhood. However, clinical presentations may vary, ranging from fatal neonatal lactic acidosis to infantile-onset Leigh syndrome, childhood-onset mitochondrial encephalomyopathy, lactic acidosis and stroke-like episodes (MELAS) syndrome and, in some cases, adult-onset encephalomyopathic syndromes of variable severity. Presentation with single organ involvement is also recognised, for example, isolated hypertrophic cardiomyopathy (HCM) or Leber's hereditary optic neuropathy (LHON).

Inherited complex I deficiency can result from mutations in either mitochondrial DNA (mtDNA) or nuclear-encoded structural subunits of the enzyme or from mutation of any of a rapidly expanding number of nuclear-encoded complex I assembly factors. To date, genetic defects have been reported for all seven mtDNA-encoded complex I subunits, 17 of the 38 nuclear-encoded subunits and nine assembly factors. Pathogenic mtDNA mutations may be maternally inherited or sporadic, while most nuclear-encoded complex I defects are inherited as autosomal recessive traits, although a small number of X-linked defects have been reported.

In this review, we discuss the structure, function and assembly of the enzyme; report the findings of a systematic review of the clinical features of 172 published patients with nuclear-encoded complex I defects, including clinical and radiological clues that may aid genetic diagnosis; and consider potential approaches to developing treatments for these devastating disorders.

\section{STRUCTURE AND FUNCTION OF COMPLEX I}

The L-shaped structure of complex I was initially revealed by electron microscopy; further detail was subsequently provided by x-ray crystallography studies of the enzyme in the bacterium Thermus thermophilus and the fungus Yarrowia lipolytica, which demonstrated the relative positions of the subunits in these organisms. ${ }^{2-4}$ Efforts are underway to determine the positions of the subunits in the mammalian enzyme by crystallising purified complex I from bovine heart. Human complex I is very similar to bovine complex I and consists of 45 different subunits (figure 1A), ${ }^{5} 14$ of which are necessary for catalytic function and are conserved in all species that have a complex I including 


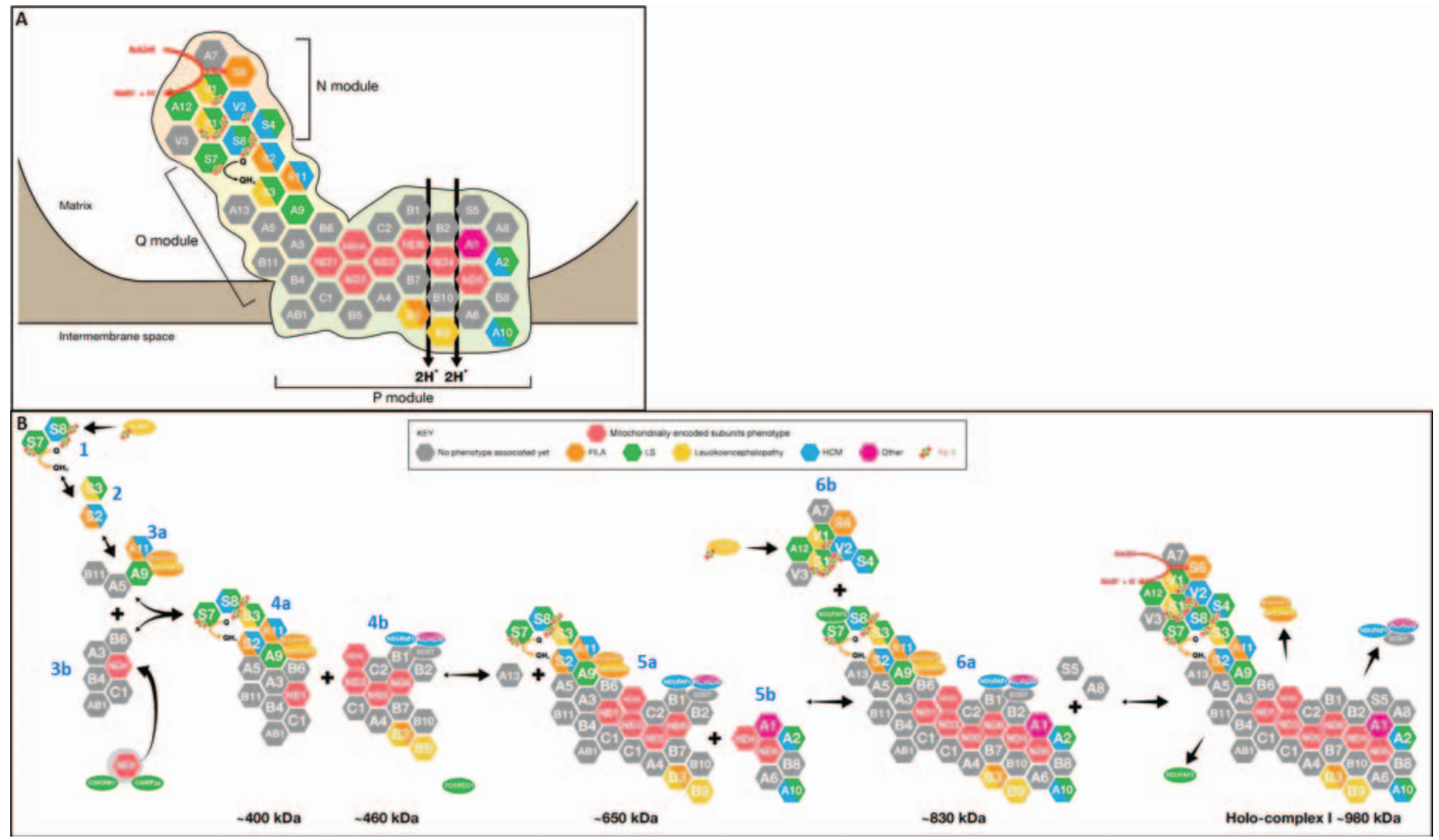

Figure 1 Structure and assembly of human mitochondrial respiratory chain complex I. (A) Structure of complex I, showing the 45 subunits (seven encoded by mitochondrial DNA and 38 by nuclear genes), colour-coded according to the clinical phenotype(s) associated with mutations of these genes (see key at the right of figure). Subunits in grey have not yet been linked to human disease. The three functional modules of the enzyme ( $\mathrm{N}$ electron accepting, $\mathrm{Q}$ ubiquinone reducing and $\mathrm{P}$ proton pumping) are shown. The oxidation of nicotinamide adenine dinucleotide by flavin mononucleotide generates a flow of electrons that are transported by the Fe-S clusters contained in the subunits NDUFV1-V2-S1-S8 and S7 to ubiquinone, which is consequently reduced to ubiquinol. The energy generated by the electron flow produces a conformational change within the holocomplex which allows for the pumping of four protons $\left(\mathrm{H}^{+}\right)$towards the intermembrane space. (B) Assembly pathway of complex I. The main subassemblies (numbered according to the scheme proposed by McKenzie and Ryan ${ }^{7}$ ) and the proposed sites of action of the nine assembly factors so far linked to human disease are indicated. Subunits and assembly factors are colour-coded according to the associated phenotype, as shown in the key at the top right.

bacteria. ${ }^{6}$ Seven of these 'core' subunits are hydrophobic and encoded by mtDNA (ND1, ND2, ND3, ND4, ND4L, ND5 and ND6), whereas the other seven are hydrophilic and encoded by nuclear DNA (NDUFV1, NDUFV2, NDUFS1, NDUFS2, NDUFS3, NDUFS7 and NDUFS8). These 14 subunits have been defined as the 'minimal enzyme', while the remaining subunits are often referred to as 'supernumerary' or 'accessory'. The minimal enzyme includes the core subunits of complex I considered essential for catalysing electron transfer from $\mathrm{NADH}$ to $\mathrm{CoO}_{10}$ and generating the proton motive force, as well as the substrate binding sites and all the known redox centres of the enzyme.

Complex I has three functional modules: the electron input or $\mathrm{N}$ module and the electron output or $\mathrm{Q}$ module, both located in the peripheral arm which protrudes into the mitochondrial matrix, and the proton translocase $\mathrm{P}$ module within the membrane arm. All seven nuclear-encoded core subunits are located within the $\mathrm{N}$ and $\mathrm{Q}$ modules, while the seven mtDNA-encoded core subunits are in the $\mathrm{P}$ module. Electrons from $\mathrm{NADH}$, which is oxidised at the matrix-protruding end of the peripheral arm, are passed to flavin mononucleotide (FMN), which is non-covalently bound to the NDUFV1 subunit, then via a chain of iron-sulphur (Fe-S) clusters to $\mathrm{CoO}_{10}$, which is reduced near the junction of the peripheral arm with the membrane arm. The energy generated by the series of electron transfer reactions within the peripheral arm is transduced, by conformational changes in the membrane arm, to pump four protons into the intermembrane space. ${ }^{4}$ These four protons contribute $\sim 40 \%$ of the electrochemical gradient that drives ATP synthesis. ${ }^{4}$ The function of the 31 nuclearencoded supernumerary subunits is still poorly understood, but putative functions include: supporting the structural stability of the enzyme by forming a 'scaffold' around the core subunits; protecting the core subunits against oxidative stress; participating in complex I assembly; and regulating the activity of the enzyme.

\section{COMPLEX I ASSEMBLY}

In addition to the structural components of complex I, there are a number of known and putative assembly factors, which chaperone the 45 subunit proteins, one FMN moiety and eight $\mathrm{Fe}-\mathrm{S}$ clusters through the intricate process of assembling the final $\sim 980 \mathrm{kDa}$ holoenzyme. ${ }^{7}$ To date, nine such assembly factors have been linked to human disease (NDUFAF1, NDUFAF2, NDUFAF3, NDUFAF4, C20ORF7, C8ORF38, nucleotide-binding protein-like (NUBPL), FOXRED1 and ACAD9). It is likely that many more complex I assembly factors will be identified considering that the much smaller complex IV, which has only 13 subunits, requires more than 15 assembly factors for its assembly. ${ }^{8}$ In support of this, phylogenetic profiling studies have identified 25 putative complex I assembly factors. ${ }^{9}$ 
Complex I assembly has been studied in various model systems: the fungus Neurospora crassa, mouse cell lines lacking mtDNA-encoded subunits; pulse-chase experiments in human cell lines in which mitochondrial protein synthesis is temporarily blocked by cycloheximide and then allowed to recommence; and in vitro mitochondrial import assays of tagged nuclearencoded complex I subunits. However, by far the most information about human complex I assembly has come from studies of fibroblasts from patients with mutations in complex I subunits and assembly factors. This has been the subject of intense research interest, which has allowed the identification of at least seven complex I assembly intermediates. ${ }^{7} 10$ So far, precise roles have been elucidated for only a few of the known complex I assembly factors. C20ORF7, C8ORF38, NDUFAF3 and NDUFAF4 have all been implicated early in the complex I assembly process, while NDUFAF1, evolutionary conserved signalling intermediate in Toll pathways (ECSIT) and ACAD9 appear to be involved at an intermediate stage and NDUFAF2 in the late stages. ${ }^{11}$ Possible functions of the various putative complex I assembly factors/chaperones include assembly of $\mathrm{Fe}-\mathrm{S}$ clusters, translational coactivation of complex I subunits and direction of nuclear-encoded complex I subunits to the correct intramitochondrial compartment (ie, to the matrix side of the enzyme or to the intermembrane space). ${ }^{7}$

The first step of complex I assembly is thought to involve incorporation of newly translated mtDNA-encoded subunits into early membrane arm assembly intermediates. ${ }^{10}$ This step is chaperoned by C20ORF7 which, together with C8ORF38, may function as a translational activator of ND1. ${ }^{12}$ Alternatively, C20ORF7 may insert ND1 into the membrane or facilitate ND1 into an early membrane arm intermediate. C20ORF7 contains a predicted S-adenosyl methioninedependent fold, suggesting that it may methylate proteins, RNA or DNA within mitochondria. ${ }^{13} 14$ Only two complex I subunits are known to be methylated: ${ }^{15}$ NDUFS2 (methylated arginine R323) and NDUFB3 (contains two or three highly conserved methylated histidines). ${ }^{16}$ Like ND1, NDUFB3 is located in the membrane arm, suggesting that posttranslational methylation may play a role in the assembly or stability of the membrane arm. Recently, C20ORF7 mutations were linked to combined deficiency of complexes I and IV, ${ }^{17}$ and knockdown of C20ORF7 expression in control cells using lentiviral-mediated $\mathrm{RNAi}^{18}$ also led to decreased complex IV activity, suggesting that C20ORF7 may be necessary for assembly of RC supercomplexes. ${ }^{17} 18$

The formation of the peripheral matrix arm begins with the assembly of four core subunits: NDUFS7 and NDUFS8 (intermediate 1), followed by NDUFS3 and NDUFS2 (intermediate 2), to form intermediate $3 \mathrm{a}$ (numbering based on nomenclature of McKenzie and Ryan; ${ }^{7}$ see figure 1B). The assembly factors NDUFAF3 (C3ORF60) and NDUFAF4 (C6ORF66), mutations of which cause fatal neonatal-onset complex I deficiency, ${ }^{19} 20$ tightly associate with intermediate $3 \mathrm{a}$, and it has been suggested that NDUFAF3 and NDUFAF4 may be involved in membrane anchoring of intermediate 2 and promoting maturation to intermediate $3 \mathrm{a}$, which also includes the NDUFA9 subunit (figure $1 \mathrm{~B}$ ). Both NDUFAF3 and NDUFAF4 remain associated with intermediates $4 \mathrm{a}(\sim 400 \mathrm{kDa}), 5 \mathrm{a}(\sim 650 \mathrm{kDa})$ and $6 \mathrm{a}(\sim 830 \mathrm{kDa})$ as complex I assembly proceeds, but are dissociated just before the formation of the mature holocomplex (figure 1B). ${ }^{19}$

NDUFAF1 (CIA30) and ECSIT mediate the next step in complex I assembly: the joining of intermediate $4 \mathrm{a}$ (a $\sim 400 \mathrm{kDa}$ subcomplex containing at least NDUFS2, NDUFS3, NDUFS7, NDUFS8 and ND1) with a second membrane arm intermediate $4 \mathrm{~b}$ of $\sim 460 \mathrm{kDa}$ (containing at least ND2, ND3 and ND6). ${ }^{10}$ Pathogenic NDUFAF1 mutations resulted in isolated complex I deficiency and cardiomyopathy in two patients, associated with stalling of complex I assembly at the $\sim 400 \mathrm{kDa}$ and $\sim 460 \mathrm{kDa}$ intermediates. ${ }^{21} 22$ No mutations have been identified in ECSIT to date, but mutations in another factor, ACAD9, which also associates with NDUFAF1 and ECSIT, appear to be a relatively common cause of complex I deficiency presenting as HCM and/or exercise intolerance.

As complex I assembly proceeds, NDUFA13 is added to the $\sim 400$ and $\sim 460 \mathrm{kDa}$ membrane arm intermediates to form intermediate $5 \mathrm{a}^{23}$ Subunits ND4 and ND5 are then assembled into the growing complex, possibly together with other subunits in the small membrane arm intermediate $5 \mathrm{~b}^{24}$ The resulting $\sim 830 \mathrm{kDa}$ intermediate $6 \mathrm{a}$ remains associated with NDUFAF1 and has been shown by co-immunoprecipitation to contain ND1, ND2, ND3, ND6, NDUFB6, NDUFA9, NDUFS3 and NDUFS7 (but not NDUFS5 or NDUFA8). ${ }^{21}$ NDUFA1, NDUFA2, NDUFA6, ${ }^{23}$ NDUFB8 and NDUFA10 ${ }^{10}$ also appear to be assembled into intermediate $6 a$ at this stage. The assembly factor NDUFAF2, mutations of which cause progressive encephalopathy, associates with the $\sim 830 \mathrm{kDa}$ complex and mediates a late step in the complex I assembly process. ${ }^{25}$

The last step for completion of fully assembled complex I is insertion of the $\sim 300 \mathrm{kDa} \mathrm{N}$ module (intermediate $6 \mathrm{~b}$ ), which provides the entry point for electrons into the complex. ${ }^{26}$ In vitro import studies demonstrated the $\mathrm{N}$ module to contain at least NDUFS1, NDUFV1, NDUFV2, NDUFV3, NDUFS4, NDUFS6, NDUFA12 and FMN (which is non-covalently bound to NDUFV1). ${ }^{10}$ Once holocomplex I assembly is complete, the assembly factors NDUFAF1, ECSIT, NDUFAF2, NDUFAF3 and NDUFAF4 dissociate from the mature holoenzyme. The electron transfer activity of complex I also requires the incorporation of eight Fe-S clusters. This step is most likely carried out by at least one assembly factor: HuIND1 (Fe-S protein required for $\mathrm{NADH}$ dehydrogenase), also known as NUBPL. NUBPL is a mitochondrial protein which binds Fe-S clusters via a conserved $\mathrm{CxxC}$ motif ${ }^{27}$ and incorporates these into various subunits of the enzyme within intermediates 1 (NDUFS7 and NDUFS8) and 6b (NDUFS1 and NDUFV1). ${ }^{27} 28$

The observation that newly synthesised subunits can be interchanged with pre-existing counterparts within mature complex I suggests that complex I assembly does not always proceed via the linear model described above, but that a subunit exchange mechanism may also be employed to repair damaged enzyme and maintain complex I homeostasis. ${ }^{24}$ It should be emphasised that the precise mechanism of complex I assembly is still debated, and may be modified as new complex I assembly factors are discovered. A further level of complexity is that it is likely that the majority of complex I exists within RC supercomplexes or 'respirasomes' (composed of at least complex I+complex III+complex IV in various stoichiometric ratios). ${ }^{29}$ Supercomplexes are thought to provide structural and functional advantages to the individual RC enzymes, including stabilisation, protection from degradation, increased efficiency of electron transport and substrate channelling, and decreased electron and proton leakage. ${ }^{30}$ It has been further suggested that complex I assembly may only occur in the context of the respirasome. $^{31}$ The existence of supercomplexes may explain the defects of other RC complexes sometimes associated with complex I mutations; for example, complex III defects in some 
patients with NDUFS4 subunit mutations ${ }^{32} 33$ and complex IV deficiency in occasional patients with defects in the complex I assembly factor C20ORF7. ${ }^{17}$

\section{COMPLEX I DEFICIENCY: CLINICAL PHENOTYPES}

Clinical presentation of complex I deficiency is extremely heterogeneous, and ranges from neonatal-onset lactic acidosis to Leigh syndrome and other encephalomyopathies, as well as multisystem disease involvement, and single organ presentations, for example, with HCM or isolated optic neuropathy. The more commonly recognised phenotypes are described below, together with the responsible genes.

\section{Fatal infantile lactic acidosis}

The earliest presentation of complex I deficiency is with congenital lactic acidosis, which may present in the neonatal period or early infancy. This disorder is typically rapidly progressive, resulting in death in infancy, and has been linked to mutations in several nuclear-encoded complex I subunits (NDUFV1, NDUFS2, NDUFS6, NDUFS8, NDUFA11 and NDUFB3) and assembly factors (NDUFAF3 and C20ORF7) (see online supplementary table S1). Few mutations have been reported in several of these genes, and so it is difficult to predict whether fatal infantile lactic acidosis (FILA) will be the characteristic clinical presentation for these genetic defects or merely reflects a severe complex I deficiency. An exception seems to apply in the case of NDUFS6 mutations, since these caused FILA in seven children from four unrelated families. ${ }^{34} 35$

\section{Leigh syndrome}

The most frequent presentation of complex I deficiency is Leigh syndrome, or subacute necrotising encephalomyelopathy. Affected children typically have normal early development but present in late infancy or early childhood with progressive neurological abnormalities related to brainstem and/or basal ganglia dysfunction. Clinical signs include respiratory abnormalities, nystagmus, ataxia, dystonia and hypotonia. Stepwise neurodevelopmental regression may follow intercurrent illnesses. Often there may be some initial recovery, but never back to the baseline neurodevelopmental trajectory. Leigh syndrome was originally defined neuropathologically (bilateral symmetrical necrotic lesions characterised by the histological quadrad of spongiosis, neuronal loss, astrocytosis and capillary proliferation $)^{36}$ but now can be diagnosed in life on the basis of the clinical features, elevated lactate levels in blood and/or cerebrospinal fluid and characteristic appearances on MRI of the brain (bilateral symmetrical hyperintensities in the basal ganglia and/or brainstem in T2 weighted sequences). ${ }^{37}$ Leigh syndrome results from severely impaired cerebral mitochondrial energy production, and is biochemically and genetically extremely heterogeneous. Although any OXPHOS defect may cause Leigh syndrome, isolated complex I deficiency is the most frequently observed biochemical abnormality, accounting for $34 \%$ of cases. ${ }^{37}$ Mutations in six mtDNA-encoded (ND1, ND2, ND3, ND4, ND5 and ND6) and 11 nuclear-encoded (NDUFS1, 2, 3, 4, 7, 8, NDUFV1, NDUFA1, 2, 9, 10) complex I subunits and four assembly factors (NDUFAF2, C8ORF38, C20ORF7 and FOXRED1) have been linked to Leigh syndrome to date (see online supplementary table S1 for details and relevant references).

\section{Leukoencephalopathy}

Other patients with infantile-onset complex I deficient encephalomyopathy have a leukodystrophy characterised by cystic white matter changes in the brain MRI. Clinical features in these children include progressive myoclonic epilepsy, episodes of vomiting, global developmental delay and regression, spasticity, dystonia, cerebellar ataxia, ptosis, ophthalmoplegia, nystagmus and optic atrophy. There may be associated macrocephaly. This phenotype has been particularly linked to mutations of two nuclear-encoded complex I subunits, NDUFV1 and NDUFS1, with five and 16 reported cases, respectively (see online supplementary table S1). Neuroradiological appearances in these patients can be confused with vanishing white matter disease. ${ }^{25}$ 38-40 A single patient with NDUFS8 mutations also presented with leukoencephalopathy, as did occasional patients with mutations in the NDUFAF4 and NUBPL assembly factors (see online supplementary table S1).

\section{Mitochondrial encephalomyopathy, lactic acidosis and stroke-like episodes}

Patients with MELAS syndrome usually have symptom-onset in childhood, with seizures, migraines, vomiting, exercise intolerance, proximal limb weakness and short stature. The first stroke-like episode (characterised by transient hemiparesis and/or hemianopsia, often preceded by focal seizures) typically occurs in the first decade of life. Isolated complex I deficiency may be seen in MELAS syndrome, particularly in individuals with ND subunit mutations. ${ }^{41}$ However, $80 \%$ of cases are caused by a common mitochondrial transfer RNA (tRNA) mutation m.3243A $>\mathrm{G}$ which may also be associated with multiple RC defects. Strokes do not seem to be particularly associated with nuclear-encoded complex I deficiencies, although stroke-like episodes were reported in two Dutch patients with $A C A D 9$ mutations, which are more usually associated with exercise intolerance and/or cardiomyopathy. ${ }^{42}$

\section{Cardiomyopathy}

Complex I deficiency may present in infancy with isolated HCM, sometimes with non-compaction of the left ventricular wall. $^{22}$ Isolated HCM has been reported with mutations in nuclear-encoded subunits (NDUFS2 and NDUFV2 $4043{ }^{44}$ ) and assembly factors (most commonly ACAD9, usually with associated exercise intolerance, ${ }^{45}$ but also NDUFAF ${ }^{22}$ ). Affected infants may succumb to FILA ${ }^{46}$ or there may be associated progressive encephalopathy, usually in the Leigh syndrome spectrum, as has been reported for mutations in several genes: NDUFS2, NDUFS4, NDUFS8, NDUFA2, NDUFA10, NDUFA11 and $A C A D 9$ (see online supplementary table S1 for details). It is possible that cardiomyopathy is under-recognised in complex I deficiency, since detailed cardiac investigations may not be performed in some patients with severe neurological presentations. Conduction defects such as Wolff-Parkinson-White syndrome have been reported in patients with both mtDNA (eg, m.13513G >A) and nuclear-encoded (eg, NDUFAF1) complex I defects. $^{21} 47$

\section{BIOCHEMICAL ASSESSMENT OF COMPLEX I}

In most centres complex I deficiency is diagnosed by spectrophotometric assay of rotenone-sensitive $\mathrm{NADH}$ : ubiquinone oxidoreductase activity in biopsied tissue (usually skeletal muscle, but another affected tissue such as cardiac muscle or liver may be biopsied). Spectrophotometric assays may also be performed in cultured skin fibroblasts from patients, but this is not an ideal tissue for investigation since many patients (particularly those with mtDNA mutations, but also some nuclear-encoded defects) do not express complex I deficiency in 
fibroblasts. In most specialist centres, fibroblasts are assayed as a second-line investigation in order to determine whether there is a systemic complex I deficiency or a tissue-specific defect. Rotenone is used in the assay because there are many $\mathrm{NADH}$ oxidoreductases in the cell, but only complex I is rotenonesensitive; residual $\mathrm{NADH}$ oxidoreductase activity after rotenone administration is subtracted from total $\mathrm{NADH}$ oxidoreductase activity in order to derive complex I activity. The activity of complex I is usually expressed as a ratio to a mitochondrial matrix enzyme (most commonly one of the Krebs cycle enzymes, such as citrate synthase or succinate dehydrogenase) to control for varying mitochondrial content between samples.

The biochemical diagnosis of complex I deficiency is not trivial and consequently there are no universally accepted diagnostic criteria. Measurement methods and reference ranges vary between laboratories: some centres use values $<30 \%$ of the control mean; others use anything below the control range; and quality assurance schemes are still in their infancy. ${ }^{48}$ Isolated complex I deficiency refers to a severe reduction of complex I, with activities of other OXPHOS complexes within (or close to) the reference range. ${ }^{1}$ A potential caveat is that the spectrophotometric $\mathrm{NADH}$ to ubiquinone oxidoreductase assay is only a measure of redox activity within the peripheral arm. Mutations of membrane arm subunits, which affect proton pumping rather than electron transfer, may theoretically result in apparently 'normal' enzyme activity. Therefore, normal complex I enzyme activity does not completely exclude the possibility of complex I deficiency, as has been demonstrated for patients with mutations in the peripherally located ND5 subunit. ${ }^{41}$ More recently mini-oxygraphy methods have been developed; while these do not give a specific measurement of complex I activity, they do allow assessment of the global oxygen consumption capacity of isolated mitochondria or intact cells. ${ }^{49} 50$ In addition, immunocapture-based methods have been used to interrogate the function of complex $\mathrm{I}^{22} 51$ The presence of individual complex I subunits may be determined by western blot analysis, and the technique of blue native gel electrophoresis (BNGE) is proving to be a powerful method for studying the assembly of the complex I holoenzyme and dissecting specific complex I assembly defects. ${ }^{10}$

\section{GENETICS OF COMPLEX I DEFICIENCY}

Complex I deficiency is genetically extremely heterogeneous and several patterns of inheritance have been observed, including maternal, autosomal recessive and X-linked. This genetic complexity, superimposed on the clinical heterogeneity discussed above, leads to considerable difficulties in establishing genetic diagnoses for patients with complex I deficiency. Complex I disease genes have been identified by candidate gene analysis (NDUFAF1, ${ }^{21}$ NDUFAF2, ${ }^{25}$ C8ORF38 ${ }^{9}$ ); genetic linkage and homozygosity mapping approaches (NDUFAF3, ${ }^{19}$ NDUFAF4, ${ }^{20}$ C20ORF7, ${ }^{18}$ FOXRED $1{ }^{51}$ ); and more recently by targeted or whole exome sequencing using next generation sequencing (NGS) techniques (NUBPL, ${ }^{52}$ ACAD9 ${ }^{53}$ ).

\section{mtDNA mutations}

Maternally inherited mutations in mtDNA-encoded complex I subunits (ND subunits) were initially linked to LHON almost 25 years ago. ${ }^{54}$ Mutations associated with LHON are homoplasmic. Subsequently, heteroplasmic mutations in ND subunits were reported in association with other clinical phenotypes, such as dystonia, MELAS and Leigh syndrome. Several recurrent mutations are recognised, ${ }^{55-58}$ and the ND5 subunit appears to be a particular hotspot for disease-causing mutations. ${ }^{41}$ Many patients have features overlapping different mitochondrial syndromes, for example some patients have LHON plus dystonia and other patients may have features overlapping MELAS, LHON and Leigh syndrome. ${ }^{41}$ A complete list of the mtDNA mutations associated with complex I deficiency can be found in the online Mitomap database (http:// www.mitomap.org/MITOMAP). Mutation pathogenicity can be especially difficult to prove for mtDNA mutations since mtDNA is extremely polymorphic and many mutations are 'private' to individual families. Factors supporting pathogenicity include heteroplasmy, segregation with disease within a family, association with a similar disease phenotype in multiple unrelated families and (the gold standard, but only possible in cases where the biochemical defect is expressed in cultured cells) demonstration of transfer of the biochemical phenotype with the mtDNA mutation in transmitochondrial cybrids. Mutation pathogenicity scoring criteria can also be helpful. ${ }^{59}$ It should be noted that many mtDNA mutations are sporadic and so the absence of a family history suggestive of maternal inheritance does not exclude the possibility of a mtDNA mutation. Studies of several cohorts of patients with complex I deficiency from around the world have suggested a fairly uniform prevalence of causative mtDNA mutations of $\sim 20 \%-$ $30 \%$. 586061 These studies indicate that sequencing mtDNA is a useful first-line genetic screening strategy in complex I deficiency, since it will be possible to make a genetic diagnosis in a significant minority; however, most cases will have a nuclear defect.

\section{Nuclear subunit mutations}

So far, mutations in 17 of the 38 nuclear-encoded complex I subunits have been reported to cause complex I deficiency, including all seven nuclear-encoded core subunits and 10 of the supernumerary subunits (see online supplementary table S1). The first nuclear subunit mutations were identified by systematically sequencing core subunit genes in a relatively large cohort of patients, ${ }^{62-65}$ and subsequently other mutations were identified by homozygosity mapping approaches in consanguineous families. ${ }^{18} 35$ To date, more than 100 affected patients have been reported: $\sim 60 \%$ with core subunit mutations and $\sim 40 \%$ with mutations in accessory subunits (see online supplementary table S1). The most frequently observed phenotypes were Leigh syndrome, leukoencephalopathy and HCM (see online supplementary table S1; figure $1 \mathrm{~A}$ and figure $2 \mathrm{~A}$ ). Most mutations were reported for NDUFS1 (24 cases) and NDUFS4 (21 cases), but mutations of NDUFV1 and NDUFS2 also occurred relatively frequently (14 and 12 cases, respectively). It is not yet known whether the preponderance of core subunit mutations reflects ascertainment bias (these subunits are more likely to be included in targeted candidate gene screening projects) or whether core subunit mutations are more likely to have functional consequences and that mild mutations in accessory subunits can be tolerated without causing clinical disease. Large-scale exome sequencing projects, which are not subject to ascertainment bias, should help to answer this question.

\section{Assembly factor mutations}

Nine nuclear-encoded complex I assembly factors have now been linked to human disease, with mutations reported in 55 patients from 32 families so far (see online supplementary table S1). The first complex I assembly defect was found using a 'genome subtraction' method, in which genes that were present in fungi with complex I but absent in fungal species 


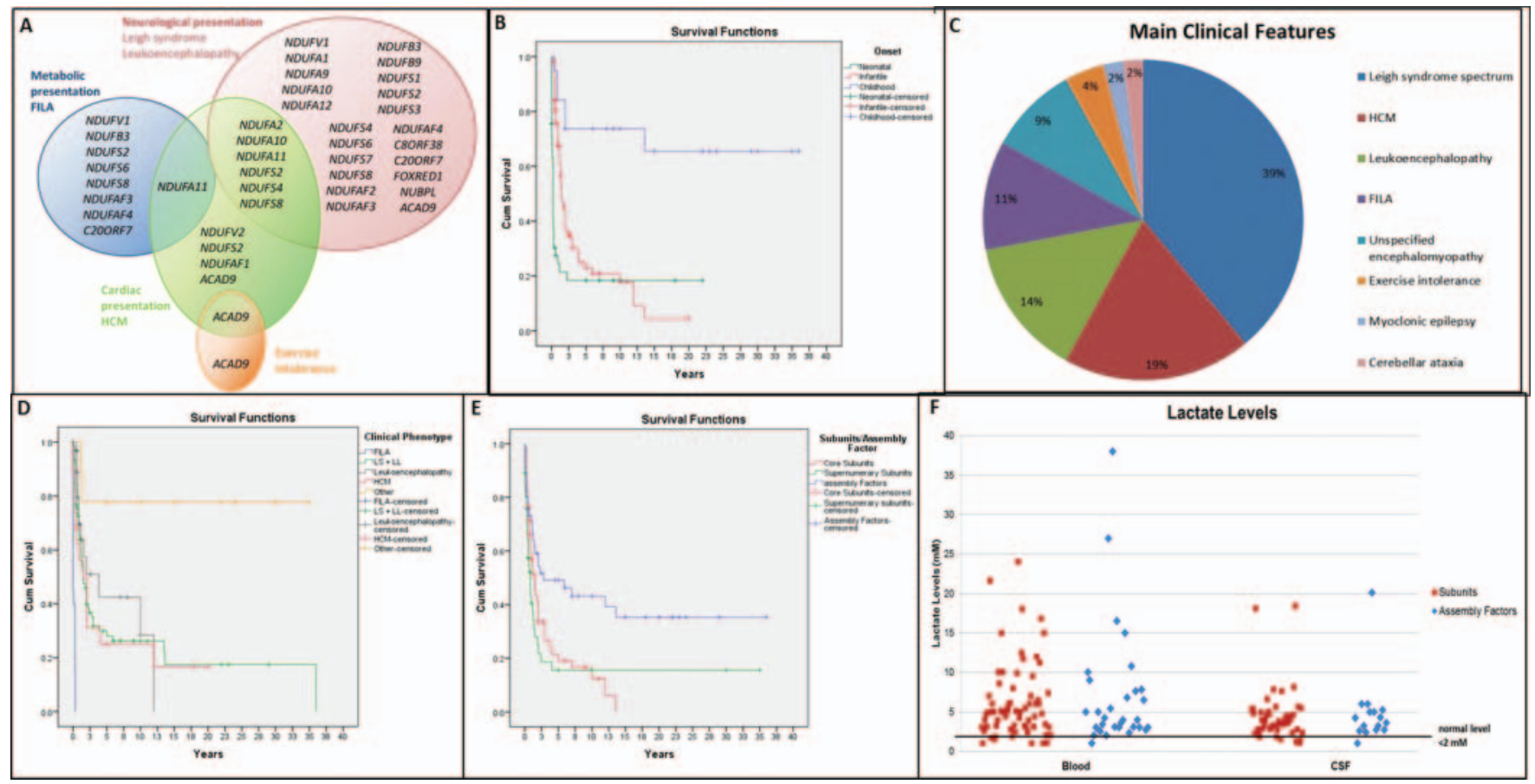

Figure 2 Genotype to phenotype correlations in nuclear-encoded complex I deficiency. (A) Venn diagram illustrating genotype to phenotype correlations between mutations in nuclear-encoded complex I subunits and assembly factors and the main clinical phenotypes (neurological, metabolic, cardiac and exercise intolerance). Note the considerable genetic heterogeneity for each clinical subgroup, and that several genetic defects are associated with more than one phenotype. (B) Kaplan-Meier survival curves for nuclear-encoded complex I deficiency, according to age of disease onset. All survival functions were calculated using SPSS V.20. (C) Pie chart illustrating the relative prevalence of the main clinical phenotypes of nuclear-encoded complex I deficiency. (D) Kaplan-Meier survival curves for nuclear-encoded complex I deficiency, according to clinical phenotype. (E) Kaplan-Meier survival curves for defects in nuclear-encoded complex I subunits, compared with assembly factor defects. (F) Blood and cerebrospinal fluid lactate concentrations (mM) reported in patients with mutations in nuclear-encoded subunits (red) and assembly factors (blue) of complex I. Normal lactate concentration is $<2 \mathrm{mM}$.

without complex I were identified as putative complex I assembly factors. This approach led to the discovery of B17.2L (now renamed NDUFAF2) mutations in a patient with progressive encephalopathy. ${ }^{25}$ Eight further patients with NDUFAF2 mutations have since been reported (see online supplementary table S1), all with similar clinical features and a characteristic neuroimaging appearance (see below). Mutations in NDUFAF1 were linked to HCM in two unrelated patients by BNGE profiling and candidate gene sequence analysis, ${ }^{21}{ }^{22}$ while homozygosity mapping revealed NDUFAF3 and NDUFAF4 to be complex I assembly factors associated with FILA or severe infantileonset encephalopathies (see online supplementary table S1). Phylogenetic profiling identified C8ORF38, C20ORF7 and FOXRED1 as candidate complex I assembly factors, and these were all subsequently linked to human disease using homozygosity mapping. ${ }^{9} 1851$ Finally, mutations in NUBPL were identified using a targeted next generation sequencing approach, ${ }^{52}$ while mutations in ACAD9 (previously thought to be involved in fatty acid oxidation) were discovered to cause complex I deficiency associated with HCM and/or exercise intolerance in a whole exome sequencing project. ${ }^{53}$

\section{Other genetic causes of complex I deficiency}

Because complex I contains the largest number of mtDNAencoded subunits, isolated complex I deficiency may be the initial biochemical defect in disorders of mtDNA replication and translation, although later in the course of these disorders there are usually multiple RC defects. The most frequent cause of defective mtDNA replication is mutation of the POLG gene encoding the catalytic subunit of DNA polymerase $\gamma$, and occasional patients with POLG mutations do present with isolated complex I deficiency. The most frequently diagnosed mtDNA translation defects affect the mitochondrial tRNA molecules, either as point mutations involving a single tRNA or large-scale rearrangements which may delete several tRNA genes. More recently, nuclear-encoded defects of mitochondrial translation have been linked to isolated complex I deficiency; for example, mutations in the MTFMT gene encoding the mitochondrial methionyl-tRNA formyltransferase. ${ }^{66}$

\section{APPROACHES TO DIAGNOSIS}

From a clinical viewpoint, the important questions in complex I deficiency are whether there are characteristic clinical features of complex I deficiency; whether any particular clinical features should arouse suspicion of specific gene defects; and finally whether specific gene defects are associated with a better or worse prognosis. Traditionally, it has been very difficult to identify genotype to phenotype correlations for mitochondrial disorders, including complex I deficiency, because of the extreme genetic heterogeneity underlying these diseases. Furthermore, even the most specialised centres will only see small numbers of patients with particular genetic defects, and so it is difficult for physicians to identify clinical clues that may point to specific diagnoses. A further source of bias is the referral pattern for individual clinicians; for example, different subgroups of patients are likely to be referred to neurologists compared with metabolic physicians or biochemical geneticists. 
We sought to address these difficulties by performing a systematic review of all cases of genetically confirmed nuclearencoded complex I deficiency in order to search for genotype to phenotype correlations and identify clinical, radiological or biochemical patterns that may help to expedite genetic diagnosis for affected individuals. Extensive literature searches of the PubMed database were performed by both authors, using the key words complex I deficiency, and names and aliases of all the nuclear-encoded complex I subunits and known assembly factors in order to obtain as near complete an ascertainment as possible of all cases published in the 14-year period, February 1998-April 2012 inclusive. All cases of genetically confirmed complex I deficiency with nuclear mutations were included in the review. Cases where only one mutation had been identified were excluded, with the exception of five hemizygous males and a single heterozygous female with mutations in the X-linked NDUFA1 gene. Other exclusion criteria were apparent duplicate reports and cases where a mutation was reported but no clinical information was supplied. In all, 65 papers were included in the review, reporting a total of 172 patients: 117 with nuclear subunit mutations and 55 with assembly factor mutations. A full list of the publications included in our meta-analysis is given in the online supplementary material.

\section{Genotype to phenotype correlations}

The overall male to female ratio observed was $1.4: 1$ but when this was broken down according to subtype of genetic defect, the proportion was 1.7:1 for nuclear subunit mutations and $1: 1$ for assembly factor mutations. The reason for the male preponderance with nuclear subunit mutations is not clear, since only a handful of cases had mutations in the X-linked NDUFA1 gene. Approximately $30 \%$ of cases had symptomonset in the neonatal period or infancy and a further $\sim 60 \%$ in early childhood, meaning that the overwhelming majority of cases with nuclear-encoded complex I defects present before 5 years of age. The distribution of age of onset was roughly the same for subgroups with nuclear subunit mutations and assembly factor defects (data not shown). In general, survival and rates of disease progression are broadly related to age at onset (figure $2 \mathrm{~B}$ ). The largest subgroup of patients presented with early-onset neurodegenerative disease with symptoms/signs compatible with the Leigh syndrome spectrum (39\% of cases). These patients had mutations in 21 different genes, so it is difficult to deduce genotype to phenotype correlations for complex I deficiency with Leigh syndrome/Leigh-like features (see online supplementary table S1; figure 1). Other patients presented with a leukoencephalopathy (14\%), an unspecified encephalomyopathy $(9 \%)$ or FILA (11\%). Overall, $19 \%$ of cases had HCM, associated with Leigh syndrome or other encephalopathic illness in over half of these cases. The remaining $8 \%$ of cases had miscellaneous clinical features, including exercise intolerance (4\%), myoclonic epilepsy $(2 \%)$, cerebellar ataxia $(2 \%)$ and recurrent lactic acidosis in a single case (figure $2 \mathrm{C}$ ). By definition, survival was poorest in those with FILA, while those with isolated exercise intolerance had the best survival. Rates of progression and survival were broadly the same for all other phenotypic subgroups (figure 2D). Overall survival appeared to be longer for patients with assembly factor mutations, which is largely attributable to patients with ACAD9 mutations and exercise intolerance (figure $2 \mathrm{E}$ ).

Defects in most genes (except where only a single case has been reported) are associated with considerable clinical heterogeneity, as illustrated in figure 2A. For example, mutations in NDUFAF1 led to fatal infantile HCM in one patient, ${ }^{22}$ but an initially severe HCM later improved in another patient who was still alive at 20 years. ${ }^{21}$ Similarly, the clinical spectrum associated with mutations in C20ORF7 ranges from neonatal-onset mitochondrial disease leading to death within a few days to adults with relatively mild Leigh syndrome associated with survival into the fourth decade. ${ }^{18} 42$ The factors contributing to this observed clinical variability are not well understood, but possible explanations include genetic modifiers, environmental factors (eg, exposure to severe viral illnesses, surgery and other metabolic stresses) and modulation of phenotype by altered immune signalling. ${ }^{22} \mathrm{~A}$ notable exception to this lack of genotype to phenotype correlation is the case of $A C A D 9$ mutations, where nearly all reported cases had HCM and/or exercise intolerance. ${ }^{45} 5367$ These patients were also characterised by clinical response to riboflavin supplementation. ${ }^{67}$ However, given the small number of patients reported with mutations in most of the complex I nuclear subunit and assembly factor genes, it is difficult to draw definitive conclusions about genotype to phenotype correlations.

\section{Neuroimaging clues}

MRI brain changes are frequently observed in patients with complex I deficiency, but in most cases are neither specific nor associated with particular genetic defects. A single-centre retrospective review of MRI scans from 30 patients with genetically confirmed complex I deficiency revealed involvement of brainstem structures in $100 \%$ of their patients and basal ganglia lesions (particularly affecting the putamina) in $90 \%$. 68 The brainstem lesions appeared as hyperintensities in the T2 and Fluid Attenuated Inversion Recovery (FLAIR) sequences and were hypointense in $\mathrm{T} 1$-weighted images. Within this series, stroke-like lesions appeared to associate with mtDNA mutations and leukoencephalopathy with nuclear subunit mutations. Cerebellar involvement was noted in $\sim 45 \%$ of cases, and occurred with both mtDNA and nuclear gene defects. ${ }^{68}$ Lebre et al reported that the combination of brainstem and striatal lesions was infrequently observed in their control groups (MT-TL1 mutations and pyruvate dehydrogenase deficiency), but comparison was not made with other RC defects causing Leigh syndrome (eg, complex IV deficiency caused by SURF1 mutations and complex $\mathrm{V}$ deficiency caused by MT-ATP6 mutations), which may present with similar MRI appearances. ${ }^{37}$

In our systematic review, detailed MRI brain reports were available for 82 of the 172 patients with nuclear-encoded complex I deficiency. Of these, only $13 \%$ had isolated basal ganglia lesions, while $28 \%$ had isolated brainstem lesions and $24 \%$ had both basal ganglia and brainstem lesions, supporting the notion that brainstem lesions may be particularly frequent in complex I deficient Leigh syndrome. However, systematic studies of other causes of Leigh syndrome are needed to determine the specificity of this observation, as discussed in the previous paragraph. A highly specific neuroimaging pattern was only seen with mutations in the NDUFAF2 assembly factor: brainstem lesions within the mamillothalamic tracts, substantia nigra, medial lemniscus, medial longitudinal fasciculus and spinothalamic tracts on T2-weighted scans. ${ }^{25} \quad 52$ 69-71 These patients did not have changes in the thalami and basal ganglia. In all, $24 \%$ of all complex I deficient cases in our review had neuroimaging features of leukoencephalopathy, most frequently associated with NDUFS1 (16 cases) and NDUFV1 (five) mutations, but also in single cases with NDUFS8, NDUFAF3 and NUBPL mutations. Cerebellar involvement was reported in nine cases, spinal cord lesions were documented in three cases and four patients had partial or complete agenesis of the corpus callosum. It is possible that other specific imaging patterns may 
emerge for subgroups of complex I deficiency, as further patients are genetically characterised. For now, MRI appearances of Leigh syndrome with brainstem and basal ganglia involvement cannot be considered sufficiently specific to avoid the need for muscle biopsy and determination of specific RC enzyme activities.

\section{Histological clues}

Most children with complex I deficiency have only minor nonspecific abnormalities in muscle histology, for example, mild lipid accumulation or fibre type disproportion. The presence of ragged red fibres should arouse suspicion of an underlying mtDNA defect, which may be a large-scale rearrangement or point mutation, or a defect of mtDNA maintenance or translation. Ragged red fibres are not usually observed in nuclearencoded complex I defects but were reported in single cases with NDUFS4, NDUFS7, FOXRED1 and NUBPL mutations. $^{32} 5272$ In addition, occasional patients with nemaline rods and complex I deficiency have been reported, ${ }^{73}$ and in one of these cases mutations of the structural subunit NDUFB3 were identified recently. ${ }^{74}$

\section{Biochemical clues}

Plasma and cerebrospinal fluid lactate were frequently elevated in the reported cases and do not appear to discriminate between different molecular genetic defects, nor was there any significant difference between patients with nuclear subunit mutations and those with assembly factor defects (figure $2 \mathrm{~F}$ ). Moreover, lactate levels did not correlate with residual complex I activity. The results of other metabolic investigations (plasma amino acid and acylcarnitine profiles and urinary organic acids) were very infrequently reported, and so it is not possible to draw any conclusions regarding whether these might provide diagnostic clues towards specific molecular genetic defects. As expected, most cases had isolated deficiency of complex I in skeletal muscle and fibroblasts (and other tissues such as heart and liver where they were assayed). In most cases, residual activity of complex I was greater in fibroblasts than in skeletal muscle. There does not appear to be any correlation between residual enzyme activity and specific genetic defect (see online supplementary table S1). In occasional cases, a more widespread OXPHOS defect was observed; for example, a recent report described complexes I and IV deficiencies in a family with C20ORF7 mutations. ${ }^{17}$ Similarly, five patients with NDUFS4 mutations were reported to have combined deficiencies of complexes I and III' 627576 and a further two cases had a combined defect of complexes I and IV. ${ }^{52}$ However, the majority of patients with mutations in these genes had isolated complex I deficiency. Possible explanations for the presence of multiple OXPHOS deficiencies in patients with complex I mutations are that increased ROS generated by dysfunctional complex I cause oxidative damage to other OXPHOS enzyme complexes or that mutation of particular complex I subunits leads to instability of RC supercomplexes, with subsequent degradation and therefore loss of activity of enzymes not assembled into supercomplexes.

Analysis of complex I assembly in patient tissues by BNGE is emerging as a method for identifying patients with abnormal subassemblies of the enzyme, and directing genetic investigations towards particular candidate genes in these patients. For example, all patients with NDUFS4 mutations reported in the literature accumulate a $\sim 830 \mathrm{kDa}$ subassembly lacking the $\mathrm{N}$ module; ${ }^{77}$ BNGE screening may be the most efficient way to detect this subgroup of patients. Patients with NDUFAF1 defects also appear to have a characteristic subassembly profile, with accumulation of the $\sim 400$ and $\sim 460 \mathrm{KDa}$ subassemblies. ${ }^{21} 22$

On the basis of the above clinical, neuroradiological, biochemical and genetic considerations, we suggest a diagnostic flowchart as depicted in figure 3.

\section{SECONDARY COMPLEX I DEFICIENCY}

A number of 'secondary' causes of complex I deficiency have been reported, most notably Parkinson's disease (PD) ${ }^{78}$ Complex I deficiency was first linked to PD in the 1980s when it became apparent that there was a high incidence of $\mathrm{PD}$ in people who had recreationally used MPTP (1-methyl-4-phenyl-1,2,3,6tetrahydropyridine), a known inhibitor of complex $\mathrm{I}^{79}$ Subsequently, a specific reduction of complex I activity was noted in postmortem substantia nigra specimens from subjects with PD. ${ }^{80}$ Mutations of mtDNA-encoded subunits of complex I have been associated with various cancers, notably thyroid oncocytic tumours. $^{81}$ Furthermore, we have recently shown that an MT-ND2 mutation appears to be involved in tumour cell resistance to the chemotherapeutic agent cisplatin. ${ }^{82}$ Complex I deficiency has also been linked to several other disease processes, including autism, ${ }^{83}{ }^{84}$ diabetes mellitus ${ }^{85}$ and a subtype of Charcot Marie Tooth disease. ${ }^{86}$ A detailed discussion of secondary complex I deficiencies is not possible here owing to space constraints; the reader is referred to a recent review by Schapira. ${ }^{78}$

\section{PATHOGENIC MECHANISMS}

While impaired ATP production is undoubtedly a major consequence of complex I deficiency, effects of mutations on the other functions of complex I are also likely to play a significant part in the pathogenesis of clinical disease. For example, complex I is a major site of ROS production and ROS are now regarded as important signalling molecules effecting communication between mitochondria and other subcellular compartments. Studies have shown that superoxide production is inversely correlated with complex I activity in complex I deficient fibroblasts. ${ }^{87}$ Furthermore, fibroblasts with very low residual activity had increased levels of ROS and fragmented mitochondrial morphology, ${ }^{88}$ suggesting that these deficient mitochondria were being targeted for autophagocytic destruction or mitophagy. ${ }^{89}$ The membrane potential is reduced in complex I deficient fibroblasts ${ }^{90} 91$ and there appears to be a linear correlation between membrane potential and increased superoxide-derived ROS levels. ${ }^{92}$ Finally, reduced ATP production was closely related to ROS levels and membrane potential, ${ }^{93}$ suggesting that all of these factors are likely to play a cumulative role in mediating disease pathogenesis.

\section{MOUSE MODELS OF COMPLEX I DEFICIENCY}

The recent development of a number of mouse models of complex I deficiency is likely to lead to advances in understanding disease mechanisms in complex I deficiency. The first mutant mouse reported to have complex I deficiency was the Harlequin mouse, which has a hypomorphic mutation in the Aif gene encoding the apoptosis-inducing factor. ${ }^{94}$ However, although the mutant mice appear to have isolated complex I deficiency, mutations in the human homologue AIFM1 have been reported to cause progressive encephalomyopathy with multiple RC defects rather than isolated complex I deficiency, ${ }^{95}$ and so the Harlequin mouse may not be the best model for human complex I deficiency. Since many knockout mouse 
Figure 3 Diagnostic flowchart for isolated complex I deficiency. Proposed pathway for genetic investigations in patients with isolated complex I deficiency. *For suggested diagnostic pathway for other oxidative phosphorylation defects, see the review by Rahman and Hanna. ${ }^{99}$ **This step is optional; because of the large number of potential candidate genes it may be preferable (and more cost-effective) to move to straight to whole exome next generation sequencing (NGS), whilst accepting the considerable bioinformatics challenges inherent to whole exome sequence analysis. See figure $2 \mathrm{~A}$ for candidate genes associated with neurological, metabolic or cardiac presentations of isolated complex I deficiency. mtDNA, mitochondrial DNA. NB nota bene.

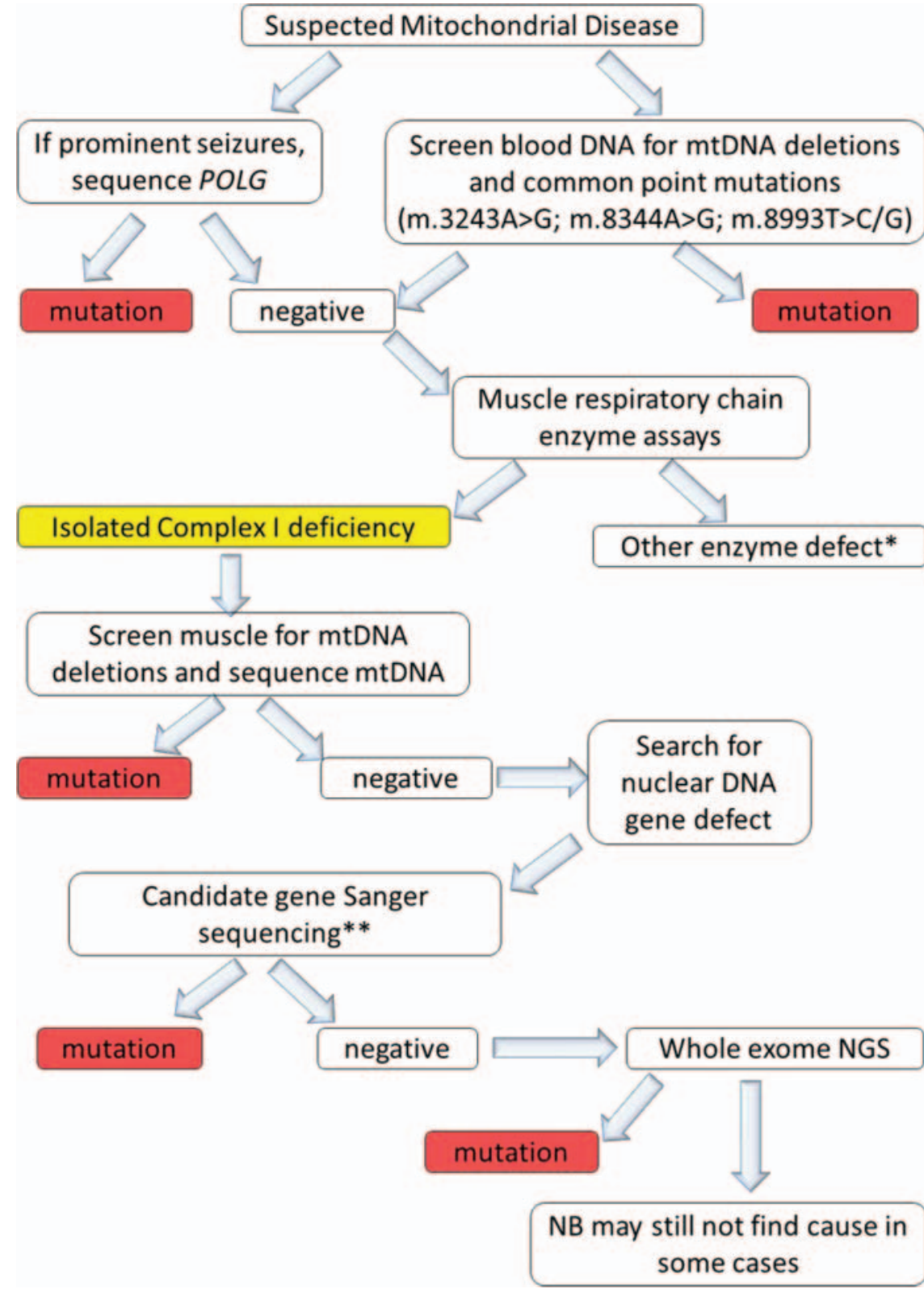

models of nuclear-encoded mitochondrial genes are embryonic lethal, mice with a conditional deletion of $N d u f s 4$ exon 2 were created using the Cre/loxP recombination system. These mice are born apparently healthy but develop ataxia from 5 weeks, leading to death from progressive encephalomyopathy by 7 weeks. ${ }^{96}$ Moreover, mice with conditional knockout of Ndufs 4 in the central nervous system have neuropathological features resembling Leigh syndrome. ${ }^{97}$ The Ndufs6 gene trap mouse model has isolated complex I deficiency manifesting as cardiomyopathy starting from postnatal day 30 , with heart failure and weight loss, sometimes causing sudden death, at approximately 4 months in the male mice and 8 months in the female animals. ${ }^{98}$ Residual complex I activity is $\sim 10 \%$ of control values, reflecting very low levels of fully assembled enzyme, and ATP production is severely reduced in isolated mitochondria using substrates needing complex I for oxidation. ROS production appears to be normal in these mutant mice. Although none of these mouse models perfectly replicates human disease (eg, human NDUFS6 mutations have never been reported to cause $\mathrm{HCM}$ ), it is anticipated that these animal models will prove to be invaluable tools in unravelling pathogenic mechanisms underlying mitochondrial disease, as well as providing a platform for preclinical trials of candidate therapies for complex I deficiency.

\section{APPROACHES TO TREATMENT}

Disappointingly, it is still the case that there are no effective curative therapies for the majority of cases of complex I deficiency, and symptomatic measures remain the mainstay of treatment for most patients. ${ }^{99}$ However, it has been known for almost 20 years that occasional patients, particularly those with a myopathic presentation, may show a clinical response to supplementation with the vitamin riboflavin $\left(B_{2}\right)^{100} 101$. Until recently, most of these patients did not have a genetic diagnosis, with the exception of a case with a complex I deficient myopathy caused by the m.3250T $>C$ mtDNA mutation. ${ }^{102}$ Riboflavin is necessary for the synthesis of FMN and flavin adenine dinucleotide. Complex I contains a single FMN moiety, non-covalently bound to the NDUFV1 subunit, but patients with NDUFV1 mutations do not appear to be particularly responsive to riboflavin. However, a number of recent 
reports have demonstrated that riboflavin responsiveness in nuclear-encoded complex I deficiency is related to ACAD9 deficiency. ACAD9 is a flavoprotein-containing enzyme which was initially implicated in long chain fatty acid oxidation ${ }^{103}$ but now appears to have a more convincing role in complex I assembly. ${ }^{45} 5367$ Increased flavin adenine dinucleotide availability as a result of riboflavin supplementation is thought to stabilise mutant flavoproteins and thereby increase their activity. ${ }^{104}$ Riboflavin supplementation was shown to increase complex I activity approximately twofold in cultured fibroblasts bearing $A C A D 9$ mutations, ${ }^{53}$ and residual muscle complex I activity also increased from $16 \%$ to $47 \%$ in a repeat biopsy taken 2 years after riboflavin therapy was commenced in one man. ${ }^{105}$ Riboflavin treatment (at doses ranging from $50 \mathrm{mg} /$ day in a neonate to $100-300 \mathrm{mg} /$ day in adults) has been documented for five patients with ACAD 9 mutations, and symptomatic improvement was reported in all cases, who were alive aged 5-24 years at the time of the reports. ${ }^{53} 67 \quad 105$ However, six patients with ACAD9 mutations reported in the literature died, between the ages of $<1$ month and 12 years. ${ }^{45} 5374$ It is not clear from the reports whether any of these children received riboflavin.

Although a therapeutic trial of riboflavin should be mandatory for all patients with complex I deficiency, most patients are unlikely to respond. There is a clear need for other treatment strategies. The most promising approaches involve antioxidant compounds or target mitochondrial biogenesis. The role of the antioxidant vitamin $\mathrm{E}$ and its analogues such as Trolox in complex I deficiency was the subject of a recent review. ${ }^{106}$ Analogues of another antioxidant, coenzyme $\mathrm{Q}_{10}$, have shown promise in arresting disease progression in LHON if given early. ${ }^{107} 108$ Mitochondrial biogenesis may be stimulated via various pharmacological agents, which all appear to act via the common pathway of stimulating the PGC1 $\alpha$ translational coactivator. ${ }^{109}$ Bezafibrate and AICAR (5-amino-1- $\beta$-Dribofuranosyl-imidazole-4-carboxamide), which both stimulate PGC1 $\alpha$, were recently shown to improve various measures of mitochondrial function in cultured skin fibroblasts from patients with nuclear-encoded complex I deficiency. ${ }^{110}$ The ketogenic diet has also been proposed to increase mitochondrial biogenesis, ${ }^{111}$ and there are anecdotal reports of benefit from a ketogenic diet in occasional patients with complex I deficiency; for example, temporary improvement of ptosis and ophthalmoplegia in a child with NDUFV1 mutations. ${ }^{112}$ However, other reports have suggested that increasing dietary fat does not improve complex I deficiency. ${ }^{113}$ Finally, two recent reports of successful gene therapy in rat models of LHON offer hope for patients with this subgroup of complex I deficiency. ${ }^{114} 115$

While the above strategies all show promise, most have not yet reached the stage of preclinical trials, and much work remains to be done in devising effective therapies for complex I deficiency. However, although developing new more effective treatments is undoubtedly important, we must not lose sight of the fact that there is an urgent need for well designed and adequately powered clinical trials of the most promising agents sooner rather than later.

\section{CONCLUSIONS}

Complex I deficiency is a common cause of childhood-onset mitochondrial disease, but the associated clinical and genetic heterogeneity leads to considerable diagnostic challenges. Recent advances in genetic techniques, particularly the availability of relatively inexpensive high-throughput whole exome next generation sequence analysis, have led to the identification of the causative gene in large numbers of patients in the last 2 years. This has allowed some tentative genotype to phenotype correlations to be made. For example, patients with $A C A D 9$ mutations typically have HCM and/or exercise intolerance, while those with NDUFAF2 defects have a subtype of Leigh syndrome with a highly specific neuroimaging appearance. These emerging genotype to phenotype correlations are important, since they will allow the diagnostic process to be more rapid, which is crucial for affected families seeking genetic counselling and prenatal diagnosis. However, some phenotypes, notably Leigh syndrome, are characterised by extreme genetic heterogeneity, and the numbers of reported patients with mutations in many of the causative genes are too small to allow genotype to phenotype comparisons to be made. An ongoing challenge is that a molecular diagnosis remains elusive for approximately $50 \%$ of patients with complex I deficiency, despite high-throughput sequencing. ${ }^{9} 74$ There are several possible explanations for this: determining which of the many variants identified by exome sequencing is pathogenic is a huge bioinformatic task; mutations may lie in introns or untranslated regulatory regions, and the assumed inheritance pattern may not be correct (eg, some patients may have de novo dominant mutations, rather than recessive mutations as is usually assumed for severe early-onset mitochondrial diseases in which mtDNA mutations have been excluded). Finally, identification of complex I deficiency should prompt initiation of riboflavin treatment since some patients, particularly those with ACADq mutations, may respond to supplementation with this vitamin. However, effective treatments are still lacking for the majority of patients with this devastating group of disorders. The recent development of several mouse models will be invaluable for preclinical trials of candidate therapies, but much work remains to be done.

Acknowledgements EF and SR are supported by Great Ormond Street Hospital Children's Charity.

Contributors Both authors performed a systematic review of the literature analysed the data, and SR wrote the manuscript.

Competing interests None.

Provenance and peer review Not commissioned; externally peer reviewed.

\section{REFERENCES}

1. Kirby DM, Crawford M, Cleary MA, Dahl HH, Dennett X, Thorburn DR. Respiratory chain complex I deficiency: an underdiagnosed energy generation disorder. Neurology 1999;52:1255-64.

2. Sazanov LA, Hinchliffe P. Structure of the hydrophilic domain of respiratory complex I from Thermus thermophilus. Science 2006;311:1430-6.

3. Efremov RG, Baradaran R, Sazanov LA. The architecture of respiratory complex I. Nature 2010;465:441-5.

4. Hunte C, Zickermann V, Brandt U. Functional modules and structural basis of conformational coupling in mitochondrial complex I. Science 2010;329:448-51.

5. Carroll J, Fearnley IM, Shannon RJ, Hirst J, Walker JE. Analysis of the subunit composition of complex I from bovine heart mitochondria. Mol Cell Proteomics 2003;2:117-26

6. Janssen RJ, Nijtmans LG, van den Heuvel LP, Smeitink JA. Mitochondrial complex I: structure, function and pathology. J Inherit Metab Dis 2006;29:499-515.

7. McKenzie M, Ryan MT. Assembly factors of human mitochondrial complex I and their defects in disease. IUBMB Life 2010;62:497-502.

8. Fontanesi F, Soto IC, Horn D, Barrientos A. Assembly of mitochondrial cytochrome c-oxidase, a complicated and highly regulated cellular process. Am J Physiol Cell Physiol 2006;291:C1129-47.

9. Pagliarini DJ, Calvo SE, Chang B, Sheth SA, Vafai SB, Ong SE, Walford GA, Sugiana C, Boneh A, Chen WK, Hill DE, Vidal M, Evans JG, Thorburn DR, Carr SA, Mootha VK. A mitochondrial protein compendium elucidates complex I disease biology. Cell 2008;134:112-23. 
10. Lazarou M, McKenzie M, Ohtake A, Thorburn DR, Ryan MT. Analysis of the assembly profiles for mitochondrial- and nuclear-DNA-encoded subunits into complex I. Mol Cell Biol 2007:27:4228-37.

11. Mimaki M, Wang X, McKenzie M, Thorburn DR, Ryan MT. Understanding mitochondrial complex I assembly in health and disease. Biochim Biophys Acta 2012;1817:851-62.

12. McKenzie M, Tucker EJ, Compton AG, Lazarou M, George C, Thorburn DR, Ryan MT. Mutations in the gene encoding C8orf38 block complex I assembly by inhibiting production of the mitochondria-encoded subunit ND1. J Mol Biol 2011:414:413-26

13. Helm M, Brule H, Degoul F, Cepanec C, Leroux JP, Giege R, Florentz C. The presence of modified nucleotides is required for cloverleaf folding of a human mitochondrial tRNA. Nucleic Acids Res 1998;26:1636-43.

14. Pintard L, Bujnicki JM, Lapeyre B, Bonnerot C. MRM2 encodes a novel yeast mitochondrial 21S rRNA methyltransferase. EMBO J 2002;21: $1139-47$.

15. Carilla-Latorre S, Gallardo ME, Annesley SJ, Calvo-Garrido J, Grana O, Accari SL, Smith PK, Valencia A, Garesse R, Fisher PR, Escalante R. MidA is a putative methyltransferase that is required for mitochondrial complex I function. J Cell Sci 2010;123(Pt 10):1674-83

16. Carroll J, Fearnley IM, Skehel JM, Runswick MJ, Shannon RJ, Hirst J, Walker JE. The post-translational modifications of the nuclear encoded subunits of complex I from bovine heart mitochondria. Mol Cell Proteomics 2005:4:693-9.

17. Saada A, Edvardson S, Shaag A, Chung WK, Segel R, Miller C, Jalas C, Elpeleg 0 . Combined OXPHOS complex I and IV defect, due to mutated complex I assembly factor C200RF7. J Inherit Metab Dis 2011;35(1):125-31.

18. Sugiana C, Pagliarini DJ, McKenzie M, Kirby DM, Salemi R, bu-Amero KK Dahl HH, Hutchison WM, Vascotto KA, Smith SM, Newbold RF, Christodoulou J, Calvo S, Mootha VK, Ryan MT, Thorburn DR. Mutation of C20orf7 disrupts complex I assembly and causes lethal neonatal mitochondrial disease. Am J Hum Genet 2008;83:468-78.

19. Saada A, Vogel RO, Hoefs SJ, van den Brand MA, Wessels HJ, Willems PH Venselaar H, Shaag A, Barghuti F, Reish 0, Shohat M, Huynen MA, Smeitink JA, van den Heuvel LP, Nijtmans LG. Mutations in NDUFAF3 (C30RF60), encoding an NDUFAF4 (C60RF66)-interacting complex I assembly protein, cause fatal neonatal mitochondrial disease. Am J Hum Genet 2009:84:718-27.

20. Saada A, Edvardson S, Rapoport M, Shaag A, Amry K, Miller C, Lorberboum-Galski $\mathrm{H}$, Elpeleg 0. C60RF66 is an assembly factor of mitochondrial complex I. Am J Hum Genet 2008;82:32-8.

21. Dunning CJ, McKenzie M, Sugiana C, Lazarou M, Silke J, Connelly A, Fletcher JM, Kirby DM, Thorburn DR, Ryan MT. Human CIA30 is involved in the early assembly of mitochondrial complex I and mutations in its gene cause disease. EMBO J 2007:26:3227-37.

22. Fassone $\mathbf{E}$, Taanman JW, Hargreaves IP, Sebire NJ, Cleary MA, Burch M, Rahman S. Mutations in the mitochondrial complex I assembly factor NDUFAF1 cause fatal infantile hypertrophic cardiomyopathy. J Med Genet 2011;48:691-7.

23. Vogel RO, Dieteren CE, van den Heuvel LP, Willems PH, Smeitink JA, Koopman WJ, Nijtmans LG. Identification of mitochondrial complex I assembly intermediates by tracing tagged NDUFS3 demonstrates the entry point of mitochondrial subunits. J Biol Chem 2007;282:7582-90.

24. Lazarou M, Thorburn DR, Ryan MT, McKenzie M. Assembly of mitochondrial complex I and defects in disease. Biochim Biophys Acta 2009:1793:78-88.

25. Ogilvie I, Kennaway NG, Shoubridge EA. A molecular chaperone for mitochondrial complex I assembly is mutated in a progressive encephalopathy. J Clin Invest 2005; 115:2784-92

26. Brandt U. Energy converting NADH:quinone oxidoreductase (complex I). Annu Rev Biochem 2006;75:69-92.

27. Bych K, Kerscher S, Netz DJ, Pierik AJ, Zwicker K, Huynen MA, Lill R, Brandt U, Balk J. The iron-sulphur protein Ind1 is required for effective complex I assembly. EMBO J 2008;27:1736-46.

28. Sheftel AD, Stehling 0, Pierik AJ, Netz DJ, Kerscher S, Elsasser HP, Wittig I Balk J, Brandt U, Lill R. Human ind1, an iron-sulfur cluster assembly factor for respiratory complex I. Mol Cell Biol 2009;29:6059-73.

29. Schagger H, Pfeiffer K. Supercomplexes in the respiratory chains of yeast and mammalian mitochondria. EMBO J 2000;19:1777-83.

30. Lenaz G, Genova ML. Structure and organization of mitochondrial respiratory complexes: a new understanding of an old subject. Antioxid Redox Signal 2010;12:961-1008

31. Moreno-Lastres D, Fontanesi F, Garcia-Consuegra I, Martin MA, Arenas J Barrientos A, Ugalde C. Mitochondrial complex I plays an essential role in human respirasome assembly. Cell Metab 2012;15:324-35

32. Budde SM, van den Heuvel LP, Janssen AJ, Smeets RJ, Buskens CA, DeMeirleir L, Van CR, Baethmann M, Voit T, Trijbels JM, Smeitink JA. Combined enzymatic complex I and III deficiency associated with mutations in the nuclear encoded NDUFS4 gene. Biochem Biophys Res Commun 2000;275:63-8.

33. Ugalde C, Janssen RJ, van den Heuvel LP, Smeitink JA, Nijtmans LG. Differences in assembly or stability of complex I and other mitochondrial OXPHOS complexes in inherited complex I deficiency. Hum Mol Genet 2004;13:659-67.
34. Kirby DM, Salemi R, Sugiana C, Ohtake A, Parry L, Bell KM, Kirk EP, Boneh A, Taylor RW, Dahl HH, Ryan MT, Thorburn DR. NDUFS6 mutations are a novel cause of lethal neonatal mitochondrial complex I deficiency. J Clin Invest 2004; 114:837-45

35. Spiegel R, Shaag A, Mandel H, Reich D, Penyakov M, Hujeirat Y, Saada A, Elpeleg 0 , Shalev SA. Mutated NDUFS6 is the cause of fatal neonatal lactic acidemia in Caucasus Jews. Eur J Hum Genet 2009;17:1200-3.

36. LEIGH D. Subacute necrotizing encephalomyelopathy in an infant. J Neurol Neurosurg Psychiatry 1951;14:216-21.

37. Rahman S, Blok RB, Dahl HH, Danks DM, Kirby DM, Chow CW, Christodoulou J Thorburn DR. Leigh syndrome: clinical features and biochemical and DNA abnormalities. Ann Neurol 1996;39:343-51.

38. Zafeiriou DI, Rodenburg RJ, Scheffer H, van den Heuvel LP, Pouwels PJ, Ververi A Athanasiadou-Piperopoulou F, van der Knaap MS. MR spectroscopy and serial magnetic resonance imaging in a patient with mitochondrial cystic leukoencephalopathy due to complex I deficiency and NDUFV1 mutations and mild clinical course. Neuropediatrics 2008;39:172-5

39. Hoefs SJ, Skjeldal OH, Rodenburg RJ, Nedregaard B, van Kaauwen EP, Spiekerkotter U, von Kleist-Retzow JC, Smeitink JA, Nijtmans LG, van den Heuvel LP. Novel mutations in the NDUFS1 gene cause low residual activities in human complex I deficiencies. Mol Genet Metab 2010;100:251-6.

40. Pagniez-Mammeri H, Lombes A, Brivet M, Ogier-de BH, Landrieu P, Legrand A, Slama A. Rapid screening for nuclear genes mutations in isolated respiratory chain complex I defects. Mol Genet Metab 2009;96:196-200.

41. Liolitsa D, Rahman S, Benton S, Carr LJ, Hanna MG. Is the mitochondrial complex I ND5 gene a hot-spot for MELAS causing mutations? Ann Neurol 2003;53:128-32.

42. Gerards M, Sluiter W, van den Bosch BJ, de WE, Calis CM, Frentzen M, Akbari $H$, Schoonderwoerd K, Scholte HR, Jongbloed RJ, Hendrickx AT, de Cl, Smeets HJ. Defective complex I assembly due to C20orf7 mutations as a new cause of Leigh syndrome. J Med Genet 2010;47(8):507-12.

43. Loeffen J, Elpeleg O, Smeitink J, Smeets R, Stockler-Ipsiroglu S, Mandel H, Sengers $\mathrm{R}$, Trijbels F, van den Heuvel L. Mutations in the complex I NDUFS2 gene of patients with cardiomyopathy and encephalomyopathy. Ann Neurol 2001:49:195-201.

44. Benit P, Beugnot R, Chretien D, Giurgea I, De Lonlay-Debeney P, Issartel JP, Corral-Debrinski M, Kerscher S, Rustin P, Rotig A, Munnich A. Mutant NDUFV2 subunit of mitochondrial complex I causes early onset hypertrophic cardiomyopathy and encephalopathy. Hum Mutat 2003;21:582-6.

45. Nouws J, Nijtmans L, Houten SM, van den Brand M, Huynen M, Venselaar H, Hoefs S, Gloerich J, Kronick J, Hutchin T, Willems P, Rodenburg R, Wanders R, van den Heuvel L, Smeitink J, Vogel RO. Acyl-CoA dehydrogenase 9 is required for the biogenesis of oxidative phosphorylation complex I. Cell Metab 2010;12:283-94.

46. Berger I, Hershkovitz E, Shaag A, Edvardson S, Saada A, Elpeleg O. Mitochondrial complex I deficiency caused by a deleterious NDUFA11 mutation. Ann Neurol 2008:63:405-8

47. Ruiter EM, Siers MH, van den Elzen C, van Engelen BG, Smeitink JA, Rodenburg $\mathrm{RJ}, \mathrm{Hol} F \mathrm{~A}$. The mitochondrial $13513 \mathrm{G}>\mathrm{A}$ mutation is most frequent in Leigh syndrome combined with reduced complex I activity, optic atrophy and/or Wolff-Parkinson-White. Eur J Hum Genet 2007;15:155-61.

48. Chen X, Thorburn DR, Wong LJ, Vladutiu GD, Haas RH, Le T, Hoppel C, Sedensky M, Morgan $\mathrm{P}$, Hahn SH. Quality improvement of mitochondrial respiratory chain complex enzyme assays using Caenorhabditis elegans. Genet Med 2011;13:794-9.

49. Moran M, Rivera H, Sanchez-Arago M, Blazquez A, Merinero B, Ugalde C, Arenas J, Cuezva JM, Martin MA. Mitochondrial bioenergetics and dynamics interplay in complex I-deficient fibroblasts. Biochim Biophys Acta 2010;1802:443-53.

50. Invernizzi F, D’Amato I, Jensen PB, Ravaglia S, Zeviani M, Tiranti V. Microscale oxygraphy reveals OXPHOS impairment in MRC mutant cells. Mitochondrion 2012:12:328-35.

51. Fassone E, Duncan AJ, Taanman JW, Pagnamenta AT, Sadowski MI, Holand T, Oasim W, Rutland P, Calvo SE, Mootha VK, Bitner-Glindzicz M, Rahman S. FOXRED1, encoding an FAD-dependent oxidoreductase complex-I-specific molecular chaperone, is mutated in infantile-onset mitochondrial encephalopathy. Hum Mol Genet 2010;19:4837-47.

52. Calvo SE, Tucker EJ, Compton AG, Kirby DM, Crawford G, Burtt NP, Rivas M, Guiducci C, Bruno DL, Goldberger OA, Redman MC, Wiltshire E, Wilson CJ, Altshuler D, Gabriel SB, Daly MJ, Thorburn DR, Mootha VK. High-throughput, pooled sequencing identifies mutations in NUBPL and FOXRED1 in human complex I deficiency. Nat Genet 2010;42:851-8.

53. Haack TB, Danhauser K, Haberberger B, Hoser J, Strecker V, Boehm D, Uziel G, Lamantea E, Invernizzi F, Poulton J, Rolinski B, luso A, Biskup S, Schmidt T, Mewes HW, Wittig I, Meitinger T, Zeviani M, Prokisch H. Exome sequencing identifies ACAD9 mutations as a cause of complex I deficiency. Nat Genet 2010;42:1131-4.

54. Wallace DC, Singh G, Lott MT, Hodge JA, Schurr TG, Lezza AM, Elsas LJ, Nikoskelainen EK. Mitochondrial DNA mutation associated with Leber's hereditary optic neuropathy. Science 1988;242:1427-30.

55. Kirby DM, Kahler SG, Freckmann ML, Reddihough D, Thorburn DR. Leigh disease caused by the mitochondrial DNA G14459A mutation in unrelated families. Ann Neurol 2000;48:102-4 
56. Kirby DM, McFarland R, Ohtake A, Dunning C, Ryan MT, Wilson C, Ketteridge D, Turnbull DM, Thorburn DR, Taylor RW. Mutations of the mitochondrial ND1 gene as a cause of MELAS. J Med Genet 2004:41:784-9.

57. McFarland R, Kirby DM, Fowler KJ, Ohtake A, Ryan MT, Amor DJ, Fletcher JM, Dixon JW, Collins FA, Turnbull DM, Taylor RW, Thorburn DR. De novo mutations in the mitochondrial ND3 gene as a cause of infantile mitochondrial encephalopathy and complex I deficiency. Ann Neurol 2004;55:58-64.

58. Lebon S, Chol M, Benit P, Mugnier C, Chretien D, Giurgea I, Kern I, Girardin E, Hertz-Pannier L, de LP, Rotig A, Rustin P, Munnich A. Recurrent de novo mitochondrial DNA mutations in respiratory chain deficiency. $J$ Med Genet 2003;40:896-9.

59. Mitchell AL, Elson JL, Howell N, Taylor RW, Turnbull DM. Sequence variation in mitochondrial complex I genes: mutation or polymorphism? J Med Genet 2006; 43:175-9.

60. Bugiani M, Invernizzi F, Alberio S, Briem E, Lamantea E, Carrara F, Moroni I, Farina L, Spada M, Donati MA, Uziel G, Zeviani M. Clinical and molecular findings in children with complex I deficiency. Biochim Biophys Acta 2004;1659:136-47.

61. Swalwell H, Kirby DM, Blakely EL, Mitchell A, Salemi R, Sugiana C, Compton AG, Tucker EJ, Ke BX, Lamont PJ, Turnbull DM, McFarland R, Taylor RW, Thorburn DR. Respiratory chain complex I deficiency caused by mitochondrial DNA mutations. Eur J Hum Genet 2011:19:769-75.

62. van den Heuvel L, Ruitenbeek W, Smeets R, Gelman-Kohan Z, Elpeleg 0, Loeffen J, Trijbels F, Mariman E, de BD, Smeitink J. Demonstration of a new pathogenic mutation in human complex I deficiency: a 5-bp duplication in the nuclear gene encoding the 18-kD (AODO) subunit. Am J Hum Genet 1998;62:262-8.

63. Loeffen J, Smeitink J, Triepels R, Smeets R, Schuelke M, Sengers R, Trijbels F, Hamel B, Mullaart R, van den Heuvel L. The first nuclear-encoded complex I mutation in a patient with Leigh syndrome. Am J Hum Genet 1998;63:1598-608.

64. Schuelke M, Smeitink J, Mariman E, Loeffen J, Plecko B, Trijbels F, Stockler-Ipsiroglu S, van den Heuvel L. Mutant NDUFV1 subunit of mitochondrial complex I causes leukodystrophy and myoclonic epilepsy. Nat Genet 1999;21:260-1

65. Triepels RH, van den Heuvel LP, Loeffen JL, Buskens CA, Smeets RJ, Rubio Gozalbo ME, Budde SM, Mariman EC, Wijburg FA, Barth PG, Trijbels JM, Smeitink JA. Leigh syndrome associated with a mutation in the NDUFS7 (PSST) nuclear encoded subunit of complex I. Ann Neurol 1999;45:787-90.

66. Haack TB, Haberberger B, Frisch EM, Wieland T, luso A, Gorza M, Strecker V, Graf E, Mayr JA, Herberg U, Hennermann JB, Klopstock T, Kuhn KA, Ahting U, Sperl W, Wilichowski E, Hoffmann GF, Tesarova M, Hansikova H, Zeman J, Plecko B, Zeviani M, Wittig I, Strom TM, Schuelke M, Freisinger P, Meitinger T, Prokisch H. Molecular diagnosis in mitochondrial complex I deficiency using exome sequencing. J Med Genet 2012:49:277-83.

67. Gerards $\mathbf{M}$, van den Bosch BJ, Danhauser K, Serre V, van WM, Wanders RJ, Nicolaes GA, Sluiter W, Schoonderwoerd K, Scholte HR, Prokisch H, Rotig A de Coo IF, Smeets HJ. Riboflavin-responsive oxidative phosphorylation complex I deficiency caused by defective ACAD9: new function for an old gene. Brain 2011;134(Pt 1):210-19.

68. Lebre AS, Rio M, Faivre $d L$, Vernerey $D$, Landrieu P, Slama A, Jardel C, Laforet $P$, Rodriguez D, Dorison N, Galanaud D, Chabrol B, Paquis-Flucklinger V, Grevent D, Edvardson S, Steffann J, Funalot B, Villeneuve N, Valayannopoulos V, de $L P$, Desguerre I, Brunelle F, Bonnefont JP, Rotig A, Munnich A, Boddaert N. A common pattern of brain MRI imaging in mitochondrial diseases with complex I deficiency. J Med Genet 2011:48:16-23.

69. Barghuti F, Elian K, Gomori JM, Shaag A, Edvardson S, Saada A, Elpeleg 0. The unique neuroradiology of complex I deficiency due to NDUFA12L defect. Mol Genet Metab 2008;94:78-82

70. Hoefs SJ, Dieteren CE, Rodenburg RJ, Naess K, Bruhn H, Wibom R, Wagena E, Willems PH, Smeitink JA, Nijtmans LG, van den Heuvel LP. Baculovirus complementation restores a novel NDUFAF2 mutation causing complex I deficiency. Hum Mutat 2009:30:E728-36.

71. Herzer M, Koch J, Prokisch H, Rodenburg R, Rauscher C, Radauer W, Forstner R, Pilz P, Rolinski B, Freisinger P, Mayr JA, Sperl W. Leigh disease with brainstem involvement in complex I deficiency due to assembly factor NDUFAF2 defect. Neuropediatrics 2010:41:30-4.

72. Lebon S, Minai L, Chretien D, Corcos J, Serre V, Kadhom N, Steffann J, Pauchard JY, Munnich A, Bonnefont JP, Rotig A. A novel mutation of the NDUFS7 gene leads to activation of a cryptic exon and impaired assembly of mitochondrial complex I in a patient with Leigh syndrome. Mol Genet Metab 2007;92:104-8.

73. Lamont PJ, Thorburn DR, Fabian V, Vajsar J, Hawkins C, Saada RA, Durling H, Laing NG, Nevo Y. Nemaline rods and complex I deficiency in three infants with hypotonia, motor delay and failure to thrive. Neuropediatrics 2004;35:302-6.

74. Calvo SE, Compton AG, Hershman SG, Lim SC, Lieber DS, Tucker EJ, Laskowski A, Garone C, Liu S, Jaffe DB, Christodoulou J, Fletcher JM, Bruno DL, Goldblatt J DiMauro S, Thorburn DR, Mootha VK. Molecular diagnosis of infantile mitochondrial disease with targeted next-generation sequencing. Sci Transl Med 2012:4:118ra10.
75. Budde SM, van den Heuvel LP, Smeets RJ, Skladal D, Mayr JA, Boelen C, Petruzzella V, Papa S, Smeitink JA. Clinical heterogeneity in patients with mutations in the NDUFS4 gene of mitochondrial complex I. J Inherit Metab Dis 2003;26:813-15

76. Rotig A, Lebon S, Zinovieva E, Mollet J, Sarzi E, Bonnefont JP, Munnich A. Molecular diagnostics of mitochondrial disorders. Biochim Biophys Acta 2004;1659:129-35.

77. Assouline Z, Jambou M, Rio M, Bole-Feysot C, de LP, Barnerias C, Desguerre I, Bonnemains C, Guillermet C, Steffann J, Munnich A, Bonnefont JP, Rotig A Lebre AS. A constant and similar assembly defect of mitochondrial respiratory chain complex I allows rapid identification of NDUFS4 mutations in patients with Leigh syndrome. Biochim Biophys Acta 2012;1822:1062-9.

78. Schapira AH. Mitochondrial diseases. Lancet 2012;379:1825-34.

79. Langston JW, Ballard P, Tetrud JW, Irwin I. Chronic Parkinsonism in humans due to a product of meperidine-analog synthesis. Science 1983;219:979-80.

80. Schapira AH, Mann VM, Cooper JM, Dexter D, Daniel SE, Jenner P, Clark JB, Marsden CD. Anatomic and disease specificity of NADH CoO1 reductase (complex I) deficiency in Parkinson's disease. J Neurochem 1990:55:2142-5.

81. Gasparre G, Porcelli AM, Bonora E, Pennisi LF, Toller M, lommarini L, Ghelli A, Moretti M, Betts CM, Martinelli GN, Ceroni AR, Curcio F, Carelli V, Rugolo M, Tallini G, Romeo G. Disruptive mitochondrial DNA mutations in complex I subunits are markers of oncocytic phenotype in thyroid tumors. Proc Natl Acad Sci U S A 2007:104:9001-6.

82. Jones AWE, Yao Z, Fassone E, Sweeney MG, Lebiedzinska M, Suski JM, Wieckowski MR, Tajeddine N, Hargreaves IP, Yasukawa T, Tufo G, Brenner C Kroemer G, Rahman S, Szabadkai G. PGC-1beta mediates adaptive chemoresistance associated with mitochondrial DNA mutations. Oncogene 2012. doi: 10.1038/onc.2012.259. [Epub ahead of print].

83. Weissman JR, Kelley RI, Bauman ML, Cohen BH, Murray KF, Mitchell RL, Kern RL, Natowicz MR. Mitochondrial disease in autism spectrum disorder patients: a cohort analysis. PLoS One 2008; 3:e3815.

84. Marui T, Funatogawa I, Koishi S, Yamamoto K, Matsumoto H, Hashimoto 0 Jinde S, Nishida H, Sugiyama T, Kasai K, Watanabe K, Kano Y, Kato N. The NADH-ubiquinone oxidoreductase 1 alpha subcomplex 5 (NDUFA5) gene variants are associated with autism. Acta Psychiatr Scand 2011;123:118-24.

85. Lefort N, Glancy B, Bowen B, Willis WT, Bailowitz Z, De Filippis EA, Brophy C, Meyer C, Hojlund K, Yi Z, Mandarino LJ. Increased reactive oxygen species production and lower abundance of complex I subunits and carnitine palmitoyltransferase 1B protein despite normal mitochondrial respiration in insulin-resistant human skeletal muscle. Diabetes 2010;59:2444-52.

86. Cassereau J, Chevrollier A, Gueguen N, Malinge MC, Letournel F, Nicolas G, Richard L, Ferre M, Verny C, Dubas F, Procaccio V, Amati-Bonneau P, Bonneau D, Reynier P. Mitochondrial complex I deficiency in GDAP1-related autosomal dominant Charcot-Marie-Tooth disease (CMT2K). Neurogenetics 2009;10:145-50.

87. Verkaart S, Koopman WJ, van Emst-de Vries SE, Nijtmans LG, van den Heuvel LW, Smeitink JA, Willems PH. Superoxide production is inversely related to complex I activity in inherited complex I deficiency. Biochim Biophys Acta 2007;1772:373-81.

88. Koopman WJ, Verkaart S, Visch HJ, van Emst-de VS, Nijtmans LG, Smeitink JA, Willems $\mathrm{PH}$. Human NADH:ubiquinone oxidoreductase deficiency: radical changes in mitochondrial morphology? Am J Physiol Cell Physiol 2007;293:C22-9.

89. Novak I. Mitophagy: A Complex Mechanism of Mitochondrial Removal. Antioxid Redox Signal 2012;17(5):794-802

90. Komen JC, Distelmaier F, Koopman WJ, Wanders RJ, Smeitink J, Willems PH Phytanic acid impairs mitochondrial respiration through protonophoric action. Cell Mol Life Sci 2007:64:3271-81.

91. Distelmaier F, Koopman WJ, Testa ER, de Jong AS, Swarts HG, Mayatepek E, Smeitink JA, Willems PH. Life cell quantification of mitochondrial membrane potential at the single organelle level. Cytometry A 2008;73:129-38.

92. Distelmaier F, Koopman WJ, van den Heuvel LP, Rodenburg RJ, Mayatepek E, Willems PH, Smeitink JA. Mitochondrial complex I deficiency: from organelle dysfunction to clinical disease. Brain 2009;132(Pt 4):833-42.

93. Visch HJ, Koopman WJ, Leusink A, van Emst-de Vries SE, van den Heuvel LW Willems PH, Smeitink JA. Decreased agonist-stimulated mitochondrial ATP production caused by a pathological reduction in endoplasmic reticulum calcium content in human complex I deficiency. Biochim Biophys Acta 2006;1762: 115-23

94. Benit P, Goncalves S, Dassa EP, Briere JJ, Rustin P. The variability of the harlequin mouse phenotype resembles that of human mitochondrial-complex I-deficiency syndromes. PLoS One 2008; 3:e3208.

95. Ghezzi D, Sevrioukova I, Invernizzi F, Lamperti C, Mora M, D'Adamo P, Novara F, Zuffardi O, Uziel G, Zeviani M. Severe X-linked mitochondrial encephalomyopathy associated with a mutation in apoptosis-inducing factor. Am J Hum Genet 2010;86:639-49.

96. Kruse SE, Watt WC, Marcinek DJ, Kapur RP, Schenkman KA, Palmiter RD. Mice with mitochondrial complex I deficiency develop a fatal encephalomyopathy. Cell Metab 2008;7:312-20. 
97. Quintana A, Kruse SE, Kapur RP, Sanz E, Palmiter RD. Complex I deficiency due to loss of Ndufs 4 in the brain results in progressive encephalopathy resembling Leigh syndrome. Proc Natl Acad Sci USA 2010;107:10996-1001.

98. Ke BX, Pepe S, Grubb DR, Komen JC, Laskowski A, Rodda FA, Hardman BM, Pitt JJ, Ryan MT, Lazarou M, Koleff J, Cheung MM, Smolich JJ, Thorburn DR. Tissue-specific splicing of an Ndufs6 gene-trap insertion generates a mitochondrial complex I deficiency-specific cardiomyopathy. Proc Natl Acad Sci USA 2012;109:6165-70.

99. Rahman S, Hanna MG. Diagnosis and therapy in neuromuscular disorders: diagnosis and new treatments in mitochondrial diseases. J Neurol Neurosurg Psychiatry 2009;80:943-53.

100. Bernsen PL, Gabreels FJ, Ruitenbeek W, Hamburger HL. Treatment of complex I deficiency with riboflavin. J Neurol Sci 1993;118:181-7.

101. Bakker HD, Scholte HR, Jeneson JA, Busch HF, Abeling NG, van Gennip AH. Vitamin-responsive complex I deficiency in a myopathic patient with increased activity of the terminal respiratory chain and lactic acidosis. J Inherit Metab Dis 1994;17:196-204

102. Ogle RF, Christodoulou J, Fagan E, Blok RB, Kirby DM, Seller KL, Dahl HH, Thorburn DR. Mitochondrial myopathy with tRNA(Leu(UUR)) mutation and complex I deficiency responsive to riboflavin. J Pediatr 1997;130:138-45.

103. He M, Rutledge SL, Kelly DR, Palmer CA, Murdoch G, Majumder N, Nicholls RD, Pei Z, Watkins PA, Vockley J. A new genetic disorder in mitochondrial fatty acid beta-oxidation: ACAD9 deficiency. Am J Hum Genet 2007;81:87-103.

104. Olsen RK, Olpin SE, Andresen BS, Miedzybrodzka ZH, Pourfarzam M, Merinero B, Frerman FE, Beresford MW, Dean JC, Cornelius N, Andersen 0, Oldfors A, Holme E, Gregersen N, Turnbull DM, Morris AA. ETFDH mutations as a major cause of riboflavin-responsive multiple acyl-CoA dehydrogenation deficiency. Brain 2007;130 (Pt 8):2045-54

105. Scholte HR, Busch HF, Bakker HD, Bogaard JM, Luyt-Houwen IE, Kuyt LP. Riboflavinresponsive complex I deficiency. Biochim Biophys Acta 1995:1271:75-83.

106. Roestenberg P, Manjeri GR, Valsecchi F, Smeitink JA, Willems PH, Koopman WJ. Pharmacological targeting of mitochondrial complex I deficiency: the cellular level and beyond. Mitochondrion 2012;12:57-65
107. Klopstock T, Yu-Wai-Man P, Dimitriadis K, Rouleau J, Heck S, Bailie M, Atawan A Chattopadhyay S, Schubert M, Garip A, Kernt M, Petraki D, Rummey C Leinonen M, Metz G, Griffiths PG, Meier T, Chinnery PF. A randomized placebo-controlled trial of idebenone in Leber's hereditary optic neuropathy. Brain 2011;134(Pt 9):2677-86.

108. Sadun AA, Chicani CF, Ross-Cisneros FN, Barboni P, Thoolen M, Shrader WD, Kubis K, Carelli V, Miller G. Effect of EPI-743 on the clinical course of the mitochondrial disease Leber hereditary optic neuropathy. Arch Neurol 2012;69:331-8.

109. Wu Z, Puigserver P, Andersson U, Zhang C, Adelmant G, Mootha V, Troy A, Cinti S Lowell B, Scarpulla RC, Spiegelman BM. Mechanisms controlling mitochondria biogenesis and respiration through the thermogenic coactivator PGC-1. Cell 1999;98:115-24

110. Golubitzky A, Dan P, Weissman S, Link G, Wikstrom JD, Saada A. Screening for active small molecules in mitochondrial complex I deficient patient's fibroblasts, reveals AICAR as the most beneficial compound. PLoS One 2011;6:e26883.

111. Bough KJ, Wetherington J, Hassel B, Pare JF, Gawryluk JW, Greene JG, Shaw R, Smith Y, Geiger JD, Dingledine RJ. Mitochondrial biogenesis in the anticonvulsant mechanism of the ketogenic diet. Ann Neurol 2006;60:223-35.

112. Laugel V, This-Bernd V, Cormier-Daire V, Speeg-Schatz C, de Saint-Martin A, Fischbach M. Early-onset ophthalmoplegia in Leigh-like syndrome due to NDUFV1 mutations. Pediatr Neurol 2007;36:54-7.

113. de Meer K, Roef MJ, de Klerk JB, Bakker HD, Smit GP, Poll-The BT. Increasing fat in the diet does not improve muscle performance in patients with mitochondrial myopathy due to complex I deficiency. J Inherit Metab Dis 2005;28:95-8.

114. Ellouze S, Augustin S, Bouaita A, Bonnet C, Simonutti M, Forster V, Picaud S Sahel JA, Corral-Debrinski M. Optimized allotopic expression of the human mitochondrial ND4 prevents blindness in a rat model of mitochondrial dysfunction. Am J Hum Genet 2008;83:373-87.

115. Marella M, Seo BB, Thomas BB, Matsuno-Yagi A, Yagi T. Successful amelioration of mitochondrial optic neuropathy using the yeast NDI1 gene in a rat animal model. PLoS One 2010;5:e11472. 


\section{Miscellaneous}

\section{Corrections}

10.1136/jmedgenet-2012-101159corr1

Fassone E, Rahman S. Complex I deficiency: clinical features, biochemistry and molecular genetics. J Med Genet. 2012;49:578-90. In the above article updated figures were not included in the proof. These will be uploaded with the article as a data supplement. 